\title{
Kashaya Foot Extrametricality as Post-Accentuation
}

\author{
Eugene Buckley \\ University of Pennsylvania
}

Kashaya, an endangered Pomoan language of northern California, has an iambic stress pattern, assigned within words and phrases. Accent regularly shifts rightward from a (CV:) foot onto the following foot, including opaque contexts when length is lost or moved by other processes. This paper brings into the analysis a class of lexical triggers of accent shift: specific stems with no long vowels on the surface that nonetheless also trigger this shift. I propose an analysis of all varieties of accent shift as alignment of constituents, requiring the head foot to follow the triggering foot. Particular evidence for alignment comes from the fact that it is blocked by phrasal resyllabification of a word-final consonant. I argue for a unified analysis of all cases that employs a diacritic at the level of the foot, which also provides an account for opacity.

Section 1 presents the basic facts of iambic footing in Kashaya. Section 2 illustrates the shift of accent from a foot consisting of a long vowel, and section 3 describes the lexically determined shift from certain stems ending in CVC. Section 4 considers analogous accent shift in several other languages, along with the ways they have been analyzed in previous work. Section 5 argues for a treatment of the Kashaya pattern as alignment of prosodic constituents, supported in section 6 by the effect of resyllabification of a word-final consonant. Section 7 proposes that the diacritic encoding lexical accent shift should be the formal mechanism for all accent triggers. Section 8 is a brief conclusion.

In this paper I largely assume an Optimality Theory approach (Prince \& Smolensky 2004), and typically refer to constraints; but reference to the edges of feet can also be formulated in other theories. Due to space limitations, I am not able to present tableaux illustrating the analysis.

\section{Kashaya footing}

In Kashaya, iambs are assigned from left to right. Footing is iterative, as evidenced by iambic lengthening (Oswalt 1961, 1988; Buckley 1994a,b, 1997). The first syllable is extrametrical by default, but this is blocked if the root is monosyllabic and unprefixed - essentially, at least one root vowel must be footed. I focus on words with syllable extrametricality, but also show monosyllabic root examples when relevant.

1.1 Stress within a word Lexical footing determines the location of iambic lengthening. When a word is uttered by itself, or patterns as a complete phonological phrase in a larger utterance, this footing also determines the location of accent. Given an initial extrametrical syllable, pitch accent ['] falls on the second syllable if it is heavy (1a, 2a), otherwise on the third syllable (1b, 2b).
a. /cu?dan- th $^{\mathrm{h}}-\mathrm{me} /$
b. /cu?dan-ad-u/

$$
\begin{aligned}
& <\text { cuP > (dán) (t }{ }^{\mathrm{h}} \text { ume?) } \\
& <\text { cup }>\text { (daná:)du } \\
& <\text { cah }>\text { (cíh)(qaw) } \\
& <\text { cah }>\text { (cimér) }
\end{aligned}
$$

\author{
'don't shoot! PL' \\ 'to keep shooting' \\ 'to place in a seated position' \\ 'sit down! IN-LAW'
}

\footnotetext{
* Examples are drawn from Oswalt $(1961,1964)$ and his unpublished dictionary and field notes, housed in the California Language Archive at the University of California, Berkeley, as well as fieldwork by the author. In the orthography used by Oswalt and followed here, $c$ is realized as the affricate $/ \mathrm{t} /$, dotted $t$ is an apico-alveolar stop, and plain $t$ is lamino-dental; but I depart from Oswalt in using [:] rather than [·] for vowel length. The phonological analysis is based on Buckley (1994a, et seq.). Collection of some data cited here was supported by a grant from the National Endowment for the Humanities: Documenting Endangered Languages program.
} 
1.2 Stress within a phrase Stress is often assigned across two or more words, or to a word and one or more following clitics (Buckley \& Gluckman 2012). This is distinct from lexical footing, in particular for words beyond the first in the phrase; iambic lengthening depends on word-internal feet. Once again, when the first word has syllable extrametricality, accent falls on the second or third syllable; but phrasally, the accented syllable is often on the second word of the phrase, or on a clitic.

a. /bihše hchoyic'-?/

b. /bihše bo?o-?k'e/
a. $\quad /$ sima $=1$ tow $/$
b. /sima miti-ad-u/$$
<\mathrm{si}>\text { (mál)(tow) }
$$$$
<\mathrm{si}>\text { (mamí)(ți:)du }
$$

$$
\begin{aligned}
& <\text { bih }>(\text { šéh })\left(\text { c }^{\text {h }} \text { oyi? }\right) \\
& <\text { bih }>(\text { šebó })(\text { ?o? }) k^{\text {he }} \text { e }
\end{aligned}
$$

'the deer died'

'will hunt deer'

'during sleep'

'to lie asleep on the ground'

I assume a basic stratal architecture, with Stem, Word, and Phrase levels (Kiparsky 2000; Bermúdez-Otero 2011). Lexical footing is assigned at the Stem and Word levels (with iambic lengthening only at the Stem level); at the Phrase level, new footing is assigned and lengthening does not apply.

\section{Accent shift with a long vowel}

If the leftmost foot is (CV:), pitch accent falls on the following foot instead. Since this occurs in combination with syllable extrametricality, the result is accent on the third or fourth syllable, depending on the weight of the third syllable. The skipped (CV:) is a nonbranching foot, parallel in basic structure to the (CVC) that takes the accent in examples such as (1a).

2.1 Within a word If a word is sufficiently long, the accent shifts onto a foot that is located within the same word as the long vowel that causes the shift. The locus of shift is marked throughout this paper with a right-pointing diacritic ${ }^{>}$following the foot on which accent would otherwise be expected to fall.
a. /dase:-wa-em/
$<\mathrm{da}>$ (se: $)^{>}($wám)
'I see (you're) washing it'
b. /dase:-weti/
$<$ da $>$ (se:) (wetí)
'although (I) washed it'
(6) a. /mat'a:-qa-ic'-th th $^{2}$
$<$ ma $>$ (ț’a: $)^{>}($qá?)(thu?)
b. /mat'a:-wi-y-e: to/
$<$ ma $>$ (t'’a: $)^{>}$(wiyé:)to
'don't let it hex you!'
'it hexed me'

2.2 Within a phrase Accent shift within a phrase - where the (CV:) foot is penultimate or final in the first word - is quite common, and provides frequent evidence for a phrasal accent domain.
a. $\quad$ /Pima:ta $=$ Pyow-a-em/
$<$ i $>$ (ma: $)^{>}($tá?)(yowam)
'the former woman SUBJ'
b. /Rima:ta našoya/
$<$ i $>>(\text { ma: })^{>}(\operatorname{taná)}($ šoya)
'young woman'
(8) a. /qahwe: wahqa-qa $=$ ?/
$<$ qah $>$ (we: $)^{>}$(wáh)(qaqa?)
'must have swallowed gum'
b. /qahwe: qac-id-u/
$<$ qah $>$ (we:) $)^{>}($qací: $)$du
'to ask for gum'

If multiple (CV:) feet occur in sequence, only the first is skipped; in other words, accent shift is not iterative.
a. /hadu: ma:duc-ya-em/
$<$ ha> (du: $)^{>}($má:)(du?)(yam)
'came home different'
b. /šiba: da-ibic-qa-w/
$<\breve{s i}>(\text { ba: })^{>}($dá: $)\left(\right.$bic $\left.^{\mathrm{h}}\right)(\mathrm{qaw})$
'went elsewhere PL'
c. $/$ kulu: $=$ ša: $=$ ?-e: $\mathrm{ma} /$
$<\mathrm{ku}>(\text { lu: })^{>}($šá:)(Pe:)ma
'you're an expert woodsman'
d. /Pama: ț'i: ma:ca?khe/
$<$ ?a $>(\text { ma: })^{>}\left(t^{\prime}\right.$ 'i:)(ma:)(ca?)k $k^{\text {he }} \quad$ 'everything of theirs'

This lack of iterativity rules out an analysis that simply avoids accent on all (CV:) feet, without any countervailing pressure to keep the accent close to the left edge.

The non-iterative nature of accent shift is a central reason that it has been analyzed in past work as foot extrametricality (Buckley 1994a, et seq.), since extrametricality is standardly limited to one constituent by 
the Peripherality Condition, or constrained by minimal violation of left-alignment. By the same token, a rule of rightward accent shift that applies one time would also have this non-iterative effect; that is roughly the pre-generative approach of Oswalt (1961).

It can be noted here that accent does fall on a domain-initial (CV:) foot when it is the only stressable element, as when relevant words occur in isolation (10a). However, accent will shift from (CV:) onto a light syllable where available, forcing the creation of a degenerate, monomoraic foot (10b).

(10) a. /qahwe:/

b. /Pima:ta/

$$
\begin{aligned}
& <\text { qah>(wé:) } \\
& <\text { ?i }>\text { (ma:) })^{>} \text {(tá) }
\end{aligned}
$$

'pitch, gum'

'woman'

2.3 Accentual domain One can imagine two essential ways of analyzing accent shift, depending on its relation to stress. The primary stress (marked by ' here) might shift, presumably by exclusion of the first foot from the metrical domain for End Rule Left, and the accent is assigned to that main stress (11a); or the main stress might remain in place, and the accent moves to the next foot within the domain, presumably as a tonal process (11b).

(11) a. ma (t’’a: ) [ ( wi 'yé: ) to ]

b. ma [('t’’a: ) ( wi yé: ) to ]

Note that syllable extrametricality, in both scenarios, is expressed as exclusion of the initial syllable /ma/ from the domain of footing; see Buckley (1994a,b, 1997, 2009) for formal analyses.

In (11a), accent shift is treated as extrametricality of the foot (Buckley 1994a, et seq.), but this is more difficult to formalize than more typical cases: it is not just any leftmost foot that is skipped, but (CV:) specifically. The extrametricality also occurs at a higher level of structure than syllable extrametricality, so it is not quite as apparent which domain the foot is excluded from. One approach is found in Buckley (1997): "Align the left edge of a line 2 constituent with the right edge of a CV: foot."

More generally, foot extrametricality is problematic as a component of the theory: few proposed examples exist, and it should perhaps be abandoned as an option (McCarthy 2003). There is also limited evidence for cumulativity or "chaining" of extrametricality at different levels (Hayes 1995), as required if Kashaya has it at both the syllable and foot levels.

The representation in (11b) does not involve exclusion from the accent domain, but requires some constraint disfavoring placement of accent on the leftmost foot. For this simple example, a constraint such as *(CV́:) would successfully favor shift to the second, branching foot. But as shown in (9), accent shift in Kashaya is not iterative; a constraint against accent on any (CV:) would predict accent on the leftmost foot that is not (CV:), such as ${ }^{*}\left\langle h a>(d u:)^{>}(m a:)^{>}\left(d^{\prime} r\right)(y a m)\right.$, in the absence of a constraint against moving too far from the left edge of the domain.

A related issue is that accent does not skip more than one foot under any circumstances, whether there is an intervening (CV:) foot or not.
a. /cuPbu-cubu-ad-ela/
$<$ cuP $>$ (bucú)(bu:)(dela)
$*<$ cup $>$ (bucu)(bu: $)^{>}$(delá)
'I walk directionlessly'
b. $\quad / p^{\text {hala }}$ qata:m-ic'-wac'-?/ $\quad<\mathrm{p}^{\mathrm{h}} \mathrm{a}>\left(\right.$ laqá) $($ ta: $)\left(\right.$ mac' $\left.^{\prime}\right)($ wa? $)$
$*<p^{\mathrm{h}} \mathrm{a}>($ laqa $)(\text { ta: })^{>}\left(\right.$mác' $\left.^{\prime}\right)($ wa? $)$
'to keep waking up again PL'

This observation has implications for the analysis I will eventually propose, formulated as accent on a foot following certain feet, including (CV:). But these facts, as well as the lack of iterativity, can both be accounted for by an effect comparable to the Peripherality Condition, which permits extrametricality only on single constituents at the edge of a domain.

Rather than appealing to extrametricality per se, however, I assume two things. First, accent shift involves exclusion of a foot from the domain in which accent is assigned to the leftmost foot, as in (11a). This assumption is consistent with unviolated End Rule Left, defined with respect to that domain - which can be considered the Accent Phrase - as well as linking of the tonal accent to the primary stress of this phrase. Second, we must have a constraint that prevents exclusion of more than one foot from the phrase; 
here I assume a foot-level equivalent of PARSE-2, which penalizes two adjacent syllables that are not parsed into foot structure (Kager 1994; see also Buckley 2009). Specifically, PARSE-2-FEET requires that at least one of any two adjacent feet be parsed into the Accent Phrase.

2.4 Opaque accent shift Opacity in Kashaya, where (CV:) is not present on the surface, leads to particular complications. A long vowel (13a) regularly shortens in a closed syllable (13b,c), but still causes accent shift - despite having an identical surface syllable structure to a verb with an underlying short vowel, as in (14).
a. /šula:m-ipba/
$<$ šu $>$ (la:)>(má?)ba
'would get sick'
b. /šula:m-qa-em/
$<$ šu $>$ (lam) ${ }^{>}$(qám)
'the one who seems sick NOM'
c. /šula:m-wi-y-e: to/
$<$ šu $>$ (lam) $>$ (wiyé:)to
'I got sick'
/duṭ'am-wi-y-e: to/
$<$ du $>$ (ț'ám)(wiye:)to
'more keep coming to me'

Second, in the process that Buckley (1994a,b) calls FOOT FLIPPING, a domain-initial expected (CV:) followed by underlying CV surfaces as a perfect iamb (CVCV:), but with accent shift. This occurs only in derived environments in verbs and only at the Stem stratum.
a. /šula:m-adad-p $\mathrm{p}^{\mathrm{h}} \mathrm{i} /$
$<$ šu $>$ (lama:) (dán') $p^{\mathrm{hi}}$
b. /šula:m-ad-uced-u/
$<$ šu $>$ (lama: $)^{>}$(ducé:)du
'after getting progressively sicker'
'to keep getting sick'
/hoṭtham-ad-uced-u/
$<$ ho>(țamá:)(duce:)du
'to keep getting warm'

Compare (15b) to the underlying short vowel in (16); the second verb has the same distribution of surface vowel length, thanks to iambic lengthening, but there is no accent shift.

Buckley $(1994 a, b)$ provides an ordered-rule analysis in which temporary, ill-formed (CV:CV) is assigned foot extrametricality, and then the vowel length moves to the second syllable to repair the structure. In an OT framework, Buckley (1999) suggests that this is a form of paradigm uniformity (outputoutput correspondence) emerging from the transparent accent shift found in related forms like (13a).

\section{Accent shift with final CVC}

Since in stems like /šula:m-/ the long vowel often surfaces, the learner has good evidence for underlying length. But in addition to this phonologically determined accent shift, there is also shift from CVC syllables in around twenty stems that provide no surface motivation for a long vowel.

3.1 Disyllables A disyllabic stem ending in a CVC syllable is normally stressed on that second syllable; the first syllable is extrametrical and CVC forms a nonbranching foot. As expected, stress falls on the first word rather than on a following clitic or word.
a. $/$ yahmot $=$ yach ma/
$<$ yah $>\left(\right.$ mó$\left.^{2}\right)\left(\mathrm{yac}^{\mathrm{h}}\right) \mathrm{ma}$
b. $/ \mathrm{kilak}^{\mathrm{h}}=\mathrm{yacol} /$
$<\mathrm{ki}>\left(\right.$ lák $\left.^{\mathrm{h}}\right)(\mathrm{yacol})$
$<$ be $>$ (hém')(ših)p ${ }^{\text {ha }}$
b. /hi?ț'it q hale/
$<$ hir $>$ (t'í') (qhale)
c. /ha?al hi?baya/
$<$ ha $>$ (?ál)(hi?)(baya)

'mountain lion AGT.PL'

'eagle AGT.OBJ'

(18) a. /behem' šihpha/

'pepperwood leaf'

'thorny plant'

'that man OBJ'

But some such stems show regular accent shift from the final CVC to the next foot, whether it is branching or not. This includes the very common word /Pacac/ with the meanings 'person, man, Indian'. For clarity, these stems are marked with the diacritic ${ }^{>}$in the underlying representation.
a. $\quad / \mathrm{Pacac}^{>}=\mathrm{yac} \mathrm{ma} /$
$<$ ?a $>(\text { ca? })^{>}\left(\right.$yác $\left.{ }^{\mathrm{h}}\right) \mathrm{ma}$
'person AGT.PL'
b. $/ \mathrm{Pacac}^{>}=\mathrm{yaco} \mathrm{k}^{\mathrm{h}} \mathrm{e} /$
$<$ ?a $>(\text { ca? })^{>}($yacó? $) k^{\text {he }}$
'person AGT.BEN' 

a. /k'abaț šihp ${ }^{\mathrm{h} a} /$
$<\mathrm{k}^{\prime} \mathrm{a}>(\mathrm{ba})^{>}\left(\mathrm{s}^{\prime} \mathrm{h}\right) \mathrm{p}^{\mathrm{h} a}$
'madrone leaf'
b. /k'abat? qale/
$<\mathrm{k}^{\prime} \mathrm{a}>(\mathrm{ba})^{>}\left(\mathrm{q}^{\mathrm{h}} \mathrm{alé}\right)$
'madrone tree'
$<$ ca $>$ (lel) $)^{>}($hí $)($baya)
'some random man'
b. /calel ${ }^{>}$ci:c'-id-e: $\mathrm{ma} /$
$<$ ca $>$ (lel) ${ }^{>}$(cic'í:)(de:)ma
'you're doing it haphazardly'

(21) a. /calel ${ }^{>}$hi?baya/

This pattern is not fully explored in the previous literature on Kashaya.

3.2 Monosyllables The same phenomenon occurs with certain monosyllabic CVC roots as well. In this case there is no syllable extrametricality, but the relation to the following clitic or word is the same.
a. $/ \mathrm{k}^{\prime}$ is ${ }^{>} \mathrm{mi}$ da/
$\left(\mathrm{k}^{\prime} \mathrm{is}\right)^{>}(\mathrm{m}$ '́?) da
'every red one'
b. /k'is' ci:c'-id-i/
(k'is)'(cic'í:)du
'keep turning red!'

Skipping of a CVC word is unexpected; the following examples illustrate the contrast between the shifting stem /hec'/ and the pattern that should follow from the metrical system.
a. $/$ hec $^{\mathrm{s}}=\mathrm{t}^{\mathrm{t}}$ in $=$ ?-e: $\mathrm{mu} /$
(hec') ')(thiné:)mu
'it's not a nail'
b. $/ \mathrm{met}=\mathrm{t}^{\mathrm{t}}$ in $=$ ?-e: $\mathrm{mu} /$
(mér)(thine:)mu
'it's not time'

3.3 Accent shift and vowel length These words ending in CVC that show accent shift never have a surface long vowel; they are not verbs, so they lack the necessary alternations under suffixation as seen for stems like /sula:m-/ in (13). But that is Oswalt's treatment of them; he posits the equivalent of / Raca:c/, /cale:1/, /k'i:s/, etc. as the underlying forms. Buckley (1994a) adopts this approach as well. In this analysis, the long vowel triggers accent shift in the same way as a surface long vowel, but always undergoes closedsyllable shortening. This characterization is not quite the same as the opacity in some realizations of /sula:m-/, where a particular morpheme surfaces in other contexts with a long vowel; here the underlying long vowel is fully abstract and never surfaces in any realization of the morpheme. ${ }^{1}$

In addition, this abstract analysis makes an incorrect prediction about the distribution of accent shift. Specifically, accent shift from a CVC syllable occurs only in word-final position. If abstract long vowels exist in the language - that is, underlying $/ \mathrm{CV}: \mathrm{C} /$ that always shortens after accent has shifted - then it should also be possible word-internally. Consider / Pima:ta/ 'woman' that has phonologically transparent accent shift in $\left\langle\right.$ ?i $>(m a:)^{>}(t a ? e ́:) m u$ 'it's a woman', as well as opaque /šula:m-qa-em/ 'the one who seems sick SUBJ' that triggers accent shift but surfaces with a short vowel in $\left\langle\breve{s} u>(\text { lam })^{>}\right.$(qám). Freely distributed abstract long vowels would predict forms such as */Pima:nta/, where no alternation will allow the long vowel to surface, but it could be inferred from accent shift in a phrase such as ${ }^{*}<2 i>(\text { man })^{>}$(tapé:) $m u$. Yet no such words exist; medial CVC in a trisyllabic stem always takes the accent, as in $<\check{s} a h>\left(p^{h} e ́ n\right) t a$ 'bluebird'. To capture this restriction, accent shift must make reference in some way to the right edge of a word, as post-accentuation. Before pursuing this analysis, let us consider previous treatments of similar patterns in other languages.

\footnotetext{
${ }^{1}$ In his manuscript dictionary, Oswalt (2005) lists a verb / Raca:c'am-/ 'embryo start to develop' and gives a possible origin in the noun /Raca:c/ 'person' plus the suffix /-am/ 'become'; this suffix is found in some verbs derived from nouns and adjectives, such as /buṭc-am-/ 'become thin' and /balay-am-/ 'become bloodshot' (with /balay/ 'blood'). If correct, this would provide a surface realization of the long vowel in proposed / Paca:c/, but there are several difficulties. First, /-am/ does not otherwise glottalize a preceding consonant as in this verb. Second, this word is rather obscure (thus of little help to a child learner) and usually refers to the development of an embryo in an egg rather than a human fetus. And third, based on associated forms that Oswalt cites, the full stem behaves metrically as a monomorpheme (i.e., it does not undergo the foot flipping of Buckley 1994). At any rate, none of the other words with final CVC accent shift have a potentially related form where the long vowel surfaces.
} 


\section{Pre- and post-accentuation}

Since accent shift in Kashaya results in accent on the foot that immediately follows a particular stem, it is a variety of post-accentuation. This phenomenon occurs in a range of languages, whether affecting the preceding or following string; a few are described here, along with some previous analyses.

4.1 Japanese A number of morphemes in Japanese induce accent on an adjacent syllable (Poser 1984). More common are pre-accenting suffixes, such as /-ke/ that is added to family names and conveys the meaning 'family bearing that name'. Since accent is realized in Japanese by a drop from H to L tone, it is marked here by ${ }^{\urcorner}$following the relevant vowel.
a. /yosida $+{ }^{<} \mathrm{ke} /$
yosida ${ }^{\top}-\mathrm{ke}$
b. /nisi'mura $+{ }^{<} \mathrm{ke} /$
nisimura'-ke
'Yoshida family'
'Nishimura family'

Notice that the accentual properties of the name when pronounced independently, which may be located on a specific syllable or entirely absent for unaccented names, are replaced by an accent preceding the suffix.

Although less common, there are also prefixes in Japanese that induce accent on the following syllable, including /ma-/ 'true'. This is a closer analogy to Kashaya.
a. $/ \mathrm{ma}^{>}+$minami/
ma-mi'nami
'due south'
b. $/ \mathrm{ma}^{>}+$yonaka $/$
ma-yo'naka
'dead of night'

Poser treats these affixes as INVISIBLE to accent assignment, which is then placed on the final or initial syllable of the visible domain. This is equivalent to the use of foot extrametricality for accent shift in Kashaya, as in Buckley (1994a,b, 1997), or perhaps the exclusion of the foot from the Accent Phrase.

A quite different approach is taken by Alderete (1999). Using the framework of Optimality Theory, he posits local ANTI-FAITHFULNESS, a transderivational (output-output) correspondence relation: the affixed stem must differ from its prominence realization in other contexts. Due to locality, this difference occurs adjacent to the triggering affix, and thus the adjacent syllable (following a prefix or preceding a suffix) bears the accent that yields the different accent pattern. The same kind of analysis cannot be applied to Kashaya for the simple reason that Kashaya is not "base-mutating" as in Japanese and in most of Alderete's other cases; rather, the accentual property is realized in whatever element happens to follow the triggering foot, and cannot normally be construed as its base. Given that this occurs at the phrasal level, in fact, the following element cannot form part of a paradigm with the trigger.

4.2 Turkish Turkish stress is final in the word by default, but some suffixes induce stress on the preceding syllable, even if many other suffixes follow. In other words, they are pre-accenting.
a. /kara-la-di-niz/
karaladi'niz
b. /kara-la-'́ma-di-niz/
kara'lamadiniz
'you PL blackened (it)'
'you PL didn't blacken (it)'

When more than one such suffix is present, the leftmost determines the location of stress; there is no limit to the distance of stress from default edge, unlike in Kashaya.

Poser (1984) analyzes this as EXTENDED INVISIBILITY, which can apply to multiple syllables; all are excluded from the domain of accentuation. Similarly, Kabak \& Vogel (2001) treat pre-accentuation as a prosodic word $(\mathrm{PrWd})$ boundary that falls before the suffix, with stress assigned to the final syllable of the PrWd domain.
a. /kara-la-di-niz/
[karaladi' niz $]_{\text {PrWd }}$
b. /kara-la-'ma-di-niz/
[kara'la] $]_{\text {PrWd }}$ madiniz

This pattern is not equivalent to that in Kashaya, since it would have the potential to exclude multiple (CV:) feet; but accent shift in Kashaya is not iterative, as illustrated in (9), and a non-peripheral (CV:) has no 
effect (10). The PrWd analysis would have the same erroneous effect as a constraint *(CV́:), seeking the leftmost foot that does not have this shape.

Inkelas \& Orgun $(1998,2003)$ posit a prespecified trochaic foot as the representation of Turkish preaccentuation; since the weak branch of a left-headed trochee aligns with the suffix, the head of the foot aligns with the preceding syllable and the stress occurs there.

$$
\text { /kara-la-('_ma)-di-niz/ kara('lama)diniz }
$$

In Kashaya, by contrast, it is the foot itself that is subject to this alignment, so the accented foot cannot overlap with the triggering morpheme.

4.3 Russian Accent in Russian nouns follows a variety of complex patterns, as discussed for example by Melvold (1989); here I mention three types. In some nouns ('cow') the accent is always on the same stem vowel; in others ('beard') it falls on an accented suffix such as the nominative singular, otherwise on the first syllable; and in still others ('lady') it is on the first vowel of a suffix, whether that suffix otherwise has the property of attracting the stress (nominative singular) or does not (nominative plural).
'cow'
'beard'
'lady'
a. ko'rov-a
borod-'a
gospož-'a
NOM. SG.
b. ko'rov-i
'borod-i
gospož-'ì
NOM. PL.

The pattern of 'lady' is post-accenting, and somewhat analogous to the Kashaya facts. Melvold (1989) analyzes the post-accenting pattern as a kind of shifting stress; the accent is lexically at the end of the stem, but moves rightward onto the suffix by means of a specific rule. This might be compared to a process in Kashaya that moves an accentual $\mathrm{H}$ tone from the stem-final foot (or a CV: foot) to the next foot head. Idsardi (1992) embodies an explicitly post-accenting formalism: a final left bracket in the metrical representation of the word, $\mathrm{xx}$ (. The left parenthesis is also used, in different locations, to represent fixed stress on a stem, which would be $x$ ( $x$ or ( $x x$ depending on the place of the stress in a disyllable. This is equivalent to alignment in OT, at least for a bracket at an edge, rather than internally. Alderete (1999), in a similar vein, posits a constraint enforcing post-stem prominence, or Align(Prom, L; Stem, R). Kashaya, on the other hand, would require alignment with the head foot as a constituent rather than with a prominence (a stressed or accented syllable), since the shifted accent can fall two syllables away if the foot is branching.

\section{Kashaya post-accentuation}

As shown in section 3, Kashaya lexicalized accent shift occurs only stem-finally, which confirms a connection to the word edge. I propose to analyze this as post-accentuation: a requirement that the accent or accentual domain follow a certain element. Ultimately, this will be expressed as a triggering property of a foot rather than a stem edge. More broadly, there are two possible sources of accent shift in Kashaya: a foot that consists of a syllable with a long vowel, or a lexeme that bears an idiosyncratic property. I argue for a unified analysis of the two cases.

5.1 Idiosyncratic accent shift as alignment To capture the idiosyncratic behavior of stems such as /Pacac/, alignment must respond somehow to lexical marking on such stems. The alignment refers not just to "some foot": that is expected anyway in most cases, since the heavy syllable would be final in an iambic foot. Rather, it must refer to the foot that bears the shifted accent. For reasons discussed in section 2.3, I treat this as the primary stress foot, or the head foot; accent is then assigned to this foot because of its status as head. For simplicity, I refer to the constraint as POST-ACCENT, and will discuss two specific forms. The first requires that the right edge of the stem be aligned with the left edge of the head foot, but only for those stems that are lexically marked as inducing accent shift, labeled here as Stem. See Pater (2007) for a similar use of alignment specific to lexically indexed morphemes.

$$
\text { Post-AcCent-Stem Align(Stem }>\text { R; HeadFoot, L) }
$$


The result is similar in effect to extrametricality, but it has a somewhat different basis. In particular, whereas extrametricality at the foot level would simply exclude a foot from the domain in which the head foot is determined, POST-ACCENT makes direct reference to the location of the head foot. High ranking of ENDRULE-LeFT ensures that the Accent Phrase is also aligned in that position.

5.2 Regular accent shift as alignment For accent shift from a (CV:) foot, the trigger is phonologically identifiable. A constraint might therefore require that the right edge of a (CV:) foot align with the left edge of the head foot, i.e. Align((CV:)Ft, R; HeadFoot, L). This differs from Post-ACCENT only in the first argument, which raises a new possibility. Suppose that a single constraint is responsible for all accent shift in Kashaya. This would have to be formulated with a foot in the first argument, since many instances of (CV:) are not stem-final, for example /Pima:ta/; whereas all stems that trigger idiosyncratic shift (such as / $\mathrm{Pacac} /$ ) also end in a foot. This further entails that the diacritic ${ }^{>}$that shifts accent is a property of a foot. Consider this new, slightly different formulation.

$$
\text { Post-Accent-Foot Align(Foot, R; HeadFoot, L) }
$$

This approach requires that certain feet in the representation acquire a diacritic that causes POST-ACCENT to have force. There are two major sources of the diacritic: a lexically marked stem (such as /Racac/), and CV: content in the foot (as in / ima:ta/). But beyond the transparent cases of surface (CV:), a diacritic presents the possibility of handling the two sorts of opacity discussed in section 2.4: closed-syllable shortening and foot flipping.

Previous analyses, in both ordered-rule and surface-constraint models (Buckley 1994a,b, 1997, 2017), have relied on the presence of a long vowel as a proximate cause of accent shift - for example, applying accent shift before a long vowel is shortened in a closed syllable, or referring by output-output correspondence to the extrametricality of a foot in a related word form. A diacritic opens up a new possibility, namely that (in ordered steps) the diacritic could be assigned early in the derivation and that is what persists, rather than the long vowel itself; or (in OT) the shared property across related forms is the diacritic rather than its effect of accent shift. Space limitations preclude pursuing these ideas in detail, but it should be clear that use of a diacritic, beyond its role in uniting the lexical and phonological triggers of accent shift, could also simplify the treatment of opaque accent shift.

\section{Resyllabification}

In this section I show that when the final consonant of an accent-shifting foot or stem resyllabifies into the next syllable, post-accentuation disappears. This supports the alignment analysis of accent shift.

6.1 Glottalizing clitics Many enclitics in Kashaya begin with a glottal stop. It surfaces as the consonant $/$ ?/ when the preceding word ends in a vowel.
a. $\quad /$ hayu $=$ ?emu/
$<$ ha $>$ (yu?é)mu
b. $/$ bihše $=$ ?-yow-a-el/
$<$ bih $>($ šé $)($ yowal $)$
'the dog SUBJ'
'the one that was a deer OBJ'

The glottal stop interacts predictably with a preceding consonant. If that consonant is a stop or affricate, the glottal stop merges with it to form a single ejective segment (33); otherwise, the glottalization disappears (34). In either case, the clitic forms a single syllabification and footing domain with the preceding material, so the stem-final consonant can surface as an onset (where glottalized sonorants are prohibited).
a. $\quad$ yahmot $=$ Pemu/
b. $/$ wayac $=$ ?-ins'e: $\mathrm{mu} /$
$<$ yah $>$ (moț'é)mu
$<$ wa $>$ (yac'ín)(s'e:)mu
c. $/$ hayu $=\mathrm{c}^{\mathrm{h}} \mathrm{ot}=$ ?-e: $\mathrm{Pa} /$
$<$ ha $>$ (yuchó)(t'e:)?a
a. $/$ ci?dom $=$ ?emu/
$<$ cir $>$ (domé)mu
b. $\quad / \mathrm{me} e=\mathrm{t}^{\mathrm{t}}$ in $=$ - $-\mathrm{e}: \mathrm{mu} /$
$<$ me $>\left(\right.$ Pethí)(ne:)mu $^{\mathrm{h}}$
c. $\quad$ birda baht $t^{\text {hel }}=$ ?el $=$ li $/$
$<$ bip $>$ (dabáh)(ț ${ }^{\text {telel }) l i}$

'the mountain lion SUBJ'

'it must be a fish net'

'I don't have a dog'

'the flower SUBJ'

'he is not your father'

'where the river is' 
The initial consonant / $/$ can often be identified with the ASSERTIVE morpheme, historically a reduced form of the verb / $\mathrm{i}$-/ ' be'. It sometimes serves a copular function but often appears merely to host a verb suffix or other clitic. For example, /=Pins'/ is clearly the assertive plus the regular SUPPOSITIONAL verb suffix /-ins'/. It is less clear whether case-marking demonstratives such as /=?emu/ contain the assertive, though this is the position of Oswalt (1961).

When the suffix that follows the assertive is consonant-initial, and the preceding segment is also a consonant, a vowel /i/ surfaces in place of the glottal stop. Buckley (1994a) analyses this as epenthesis in the three-consonant cluster /C?_C/, followed by the regular outcome of post-consonantal / $/$ /, including glottalization. For present purposes, however, I include the surface /i/ in the underlying form of the clitic; this assumption does not meaningfully alter the analysis, since the clitic-initial sequence / $\mathrm{i} /$ shows the same behavior as the sequence $/ \mathrm{Re} /$ that cannot be treated as epenthesis.

$$
\begin{aligned}
& \text { a. } \quad / q^{\text {ha }}{ }^{2} b_{e} q^{\text {hac }}=\text { ?i-yow-a-el } /<q^{\text {ha }}>\left(\text { beq }^{\text {há}}\right)\left(c^{\prime} \text { iyo }\right)(\text { wal }) \\
& \text { b. } \quad \text { bahcil }=\text { ?i-yow-a-em } / \quad<\text { bah }>(\text { cili) })(\text { yowam })
\end{aligned}
$$

'the former sharp-skinned hawk OBJ' 'those who were far away SUBJ'

6.2 Loss of accent shift A striking property of the resyllabification that occurs with a glottalizing clitic - not previously discussed in the literature - is that any effect of accent shift is lost. This is true whether the preceding syllable contains a clearly motivated underlying long vowel (36) or is an idiosyncratic lexical item (37). Both cases pattern just like the non-shifting stems in (33) and (34).
a. /šula:m-? =?i-yow-a-em/
$<$ šu $>$ (lamí)(yowam)
'the one who was sick SUBJ'
b. $\quad /$ mace:-w $=$ ?i-qan/
*< šu $>$ (la) $>$ (miyó)(wam)
$<$ ma $>$ (cewí)(qan)
$*<$ ma $>$ (ce) ${ }^{>}$(wiqán)
'apparently protected'
a. $\quad / \mathrm{Pacac}^{>}=\mathrm{Pemu} /$
$<$ Pa $>$ (cac'é)mu
$*<\mathrm{aa}>(\mathrm{ca})^{>}$(c'emú)
b. $\quad /$ Racac ${ }^{>}=$?i-yow-a-el/
$<$ ?a $>$ (cac'í)(yowal)
$*<$ a $>$ (ca) ${ }^{>}$(c'iyó)(wal)

'the person SUBJ'

'the former person OBJ'

The verbs in (36) have closed-syllable shortening due to the absolutive suffix /-?/ or /-w/ that is added to the stem; any opacity in accent shift would be similar to that found in cases such as (13). But in this context there is no opacity; the expected accent shift does not occur in the presence of resyllabification.

6.3 Role of resyllabification I argue that the loss of accent shift is the straightforward result of resyllabification. Lexemes such as / Pacac/ require post-accentuation, but this effect is mediated by prosody, akin to crisp edges (Ito \& Mester 1999). The right edge of / $\mathrm{Racac} /$, whether interpreted as the stem directly or a foot that itself is normally aligned with the stem, cannot remain right-aligned with a foot if the final segment resyllabifies into the onset of the following syllable. Undominated ONSET means that POSTACCENT cannot be satisfied, rendering it inert. This is true without even taking into account the effect of glottal fusion, which further obscures the boundary between the stem and the clitic. The same insight seems unavailable in other approaches, whether extrametricality or tone shift, since they do not rely on the right edge of the constituent that is responsible for accent shift.

It is noteworthy that the underlying long vowel fails to surface even in the open syllable that arises after resyllabification. If (CV:) persists long enough to cause accent shift here (as in the approach of Buckley 1994a,b), why is the length absent? But these facts make sense under the diacritic analysis, which does not rely on the continued presence of (CV:) to condition the accent shift; instead, the length is generally lost before the Phrase level.
a. /šula:m-? bane-maduc-?/
$<$ šu $>\left(\right.$ lam') ${ }^{>}($bané $)(\mathrm{ma}:)(\mathrm{du}$ ?)
'arrived and fell down sick'
b. /šula:m-? =?i-yow-a-el/ $\quad<$ šu $>($ lamí)(yowal)
'the one who was sick OBJ' 

a. /dat'e:1-? tubic-ic'-?/
$<$ da $>\left(\text { t'el' }^{\prime}\right)^{>}($tubí) $($yir)
'to start to smear'

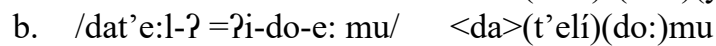
'they say s/he smeared it'

This outcome emphasizes the dubiousness of length as the direct trigger of accent shift: where a long vowel cannot surface (in a closed syllable), the accent shifts; but in a location where it could surface (before a glottal clitic), the length disappears and the accent does not shift.

\section{A unified analysis}

At first glance, we find disjunct loci of accent shift: the right edge of certain stems, and the right edge of (CV:) feet. There is also considerable opacity: accent shift triggered by (CVC) that arises from closedsyllable shortening, and by (CVCV:) that results from underlying CV: + CV by foot flipping. But in every case, the trigger corresponds to the right edge of a foot. And since the nature of accent shift is that it requires accent on the following foot, it is reasonable to suppose that the trigger is a foot in all cases.

7.1 Feet and diacritics The transparent accent shift from (CV:) feet is already rather unusual crosslinguistically - accent is normally attracted to long vowels - so it is perhaps not surprising it might require a somewhat ad-hoc solution in Kashaya: a diacritic on the foot, activating an alignment constraint. This involves an interaction with another foot, of course, so it occurs at the same prosodic level. The remaining cases can all take the same approach, i.e. a diacritic on a foot. This addresses the opacity problem, since the proximate trigger of accent shift is the diacritic, not the vowel length that may have been eliminated by the time the accent shift occurs (often at the Phrasal level).

For lexical triggers like/Racac/, the right stem boundary is also a foot boundary: all these stems end in $\mathrm{CVC}$, which in turn must always be final in a quantity-sensitive iambic foot. The lexical diacritic actually associates with this foot, thanks to the perfect right-alignment of the stem and the foot that is usually true. But post-accentuation occurs only if that foot maintains its integrity. More specifically, material can be added, as in the closed-syllable shortening in (40b) and (41b).
a. /q⿳os'a: Pahqol/
$<\mathrm{q}^{\mathrm{h}} \mathrm{o}>(\text { s'a: })^{>}($Páh $)(\mathrm{qol})$
b. $/ \mathrm{q}^{\mathrm{h}} \mathrm{Os}$ 'a: $=$ ?-yow-a-em/ $<\mathrm{q}^{\mathrm{h}} \mathrm{O}>\left(\mathrm{s}^{\prime} \mathrm{a} \text { ? }\right)^{>}($yowám)
$<$ qa $>$ (li: $)^{>}($dimá)ti
b. $\quad /$ qali: $=$ ltow $/$
$<\mathrm{qa}>(\text { lil) })^{>}$(tów)

'a long winter'

'formerly in winter SUBJ'

(41) a. /qali: dima-ti/

'in order to hold high'

'from above'

In contrast, material cannot moved out of the foot (as in resyllabification) without forcing creation of new foot structure: loss of the coda consonant implies loss of its mora and disruption to the syllable that heads the foot (compare the PARASITIC DELINKING of Hayes 1989). When the foot structure is disrupted, and the match between the right edge of the stem and foot is broken, the diacritic is lost (or cannot have any effect). This is also true for underlyingly long vowels; the assignment of the diacritic to the (CV:) foot must precede closed-syllable shortening, but this diacritic is also lost or ineffectual under resyllabification.

7.2 Lexical exceptionality Lexical exceptionality is often claimed to be associated with morphemes, rather than phonological objects (Pater 2007, Gouskova 2012), but it has also been argued that lexically indexed constraints are sometimes affiliated with phonological elements (Round 2017). In Kashaya, we cannot rely on morphemes alone; many long vowels arise from elision across morphemes, and behave the same way as underlying long vowels. But the diacritic on (CV:) feet is predictable, and should not be specified underlyingly as exceptionality. The only situation requiring an underlying diacritic is indeed linked to particular morphemes, such as / Racac/; but I suggest it is transferred to the foot that is rightaligned with this stem.

Although it is not necessary (or perhaps permissible) to mark feet as underlyingly exceptional in Kashaya, the analysis proposed does posit a diacritic that is ultimately affiliated with a phonological constituent - here, the foot rather than the more typical segment. An important remaining question is the mechanism that assigns this diacritic to the foot. I have no formal proposal to make on this point; typologically informed predictions must await similar cases in other languages. 
7.3 Restriction to CVC Only C-final words have lexical post-accentuation; thus, there is no word like */bihše ${ }^{>} /$with accent shift parallel to attested $/ \mathrm{Racac}^{>} /$. Under the analysis that requires transfer of the stemspecified diacritic to a right-aligned foot, this restriction follows naturally, since with extrametricality, the final light syllable of actual /bihše/ 'deer' will not form a foot by itself and no diacritic could be transferred under conditions of alignment. (If the word occurs alone, it is footed $\langle b i h\rangle(\tilde{s} e ́)$, but by definition there is no following material to receive a shifted accent; compare (10).) There is also no detectable lexical accent shift for words such as /qali:/ 'above, high', since the long vowel already causes the same effect.

Another situation in which no lexical accent shift occurs is longer stems such as /buṭaqa/ 'bear' and /sulemaț/ 'rope'. In principle, we might expect to find lexical items of the type ${ }^{*}<s u>(\text { lemat })^{>}$with accent shift from this stem, which does align with a foot. But here we can rely again on the fact that the diacritic has to transfer to the foot itself, by the proviso that only nonbranching feet - that is, (CV:) and (CVC) - are able to take this diacritic, making the branching foot in trisyllabic stems ineligible.

Of course, in the more complex case of foot flipping (15), a branching foot of the shape (CVCV:) eventually does show accent shift. But as argued by Buckley (1994a,b), the initial phonological context for this shift is (CV:), to which a following CV is adjoined, with subsequent movement of a mora. These steps are more challenging to implement in an OT context; but if these steps are not permitted, that leaves us with a rather different source of accent shift in foot-flipping words, such as an output-output correspondence (Buckley 1999); and this correspondence effect might easily bypass the nonbranching restriction that applies to the direct assignment of the diacritic.

\section{Conclusion}

Kashaya accent shift occurs in several contexts. One situation is entirely transparent, with (CV:) feet. Another might be called lexically "transparent", with certain stems that have a stem-final (CVC) foot; this is still clearly mediated by prosody, as seen by the loss of shift under resyllabification. Two contexts are opaque: a (CVC) that arises from closed-syllable shortening of $(\mathrm{CV}: \mathrm{C})$, and (CVCV:) resulting from underlying $\mathrm{CV}$ : $+\mathrm{CV}$.

I have argued for an analysis as alignment to a diacritically marked foot. A specific advantage of the alignment approach in Kashaya is that it avoids positing abstract underlying vowel length that never surfaces in any realization of the morpheme. The inherent connection to edges accounts for the lack of word-internal abstract length. Extending the diacritic to all instances of accent shift, even those attributable to surface vowel length, unifies the divergent sources of shifted accent, including opaque triggers that have undergone shortening in closed syllables. Importantly, reference to alignment of edges accounts for the loss of accent shift under resyllabification. A remaining question is how this kind of prosodic diacritic fits into a larger theoretical picture; only additional examples from other languages will allow us to pursue a clear answer to this question.

\section{References}

Alderete, John. 1999. Morphologically governed accent in Optimality Theory. Amherst, MA: University of Massachusetts dissertation.

Bermúdez-Otero, Ricardo. 2011. Cyclicity. In Marc van Oostendorp, Colin J. Ewen, Elizabeth V. Hume \& Keren Rice (eds.), The Blackwell companion to phonology, vol. 4, 2019-2048. Malden, MA \& Oxford: Wiley-Blackwell.

Buckley, Eugene. 1994a. Theoretical aspects of Kashaya phonology and morphology. Stanford, CA: Center for the Study of Language and Information.

Buckley, Eugene. 1994b. Persistent and cumulative extrametricality in Kashaya. Natural Language and Linguistic Theory 12. 423-464.

Buckley, Eugene. 1997. Optimal iambs in Kashaya. Rivista di Linguistica 9. 9-52.

Buckley, Eugene. 1999. Uniformity in extended paradigms. In Ben Hermans \& Marc van Oostendorp (eds.), The derivational residue in phonological Optimality Theory, 81-104. Amsterdam \& Philadelphia: John Benjamins.

Buckley, Eugene. 2009. Locality in metrical phonology. Phonology 26. 389-435.

Buckley, Eugene. 2017. Global effects in Kashaya prosodic structure. In Vera Gribanova \& Stephanie Shih (eds.), The morphosyntax-phonology connection: Locality and directionality at the interface, 113-140. Oxford: Oxford University Press. 
Buckley, Eugene \& John Gluckman. 2012. Syntax and prosody in Kashaya phrasal accent. University of Pennsylvania Working Papers in Linguistics 18(1), article 4. <http://repository.upenn.edu/pwpl/vol18/iss 1/4>

Gouskova, Maria. 2012. Unexceptional segments. Natural Language and Linguistic Theory 30. 79-133.

Hayes, Bruce. 1989. Compensatory lengthening in moraic phonology. Linguistic Inquiry 20. 253-306.

Hayes, Bruce. 1995. Metrical stress theory: Principles and case studies. Chicago: University of Chicago Press.

Idsardi, William, 1992. The computation of prosody. Cambridge, MA: MIT dissertation.

Inkelas, Sharon \& Cemil Orhan Orgun. 1998. Level (non)ordering in recursive morphology: Evidence from Turkish. In Steven Lapointe, Diane Brentari \& Patrick Farrell (eds.), Morphology and its relation to phonology and syntax, 360-392. Stanford, CA: Center for the Study of Language and Information.

Inkelas, Sharon \& Cemil Orhan Orgun. 2003. Turkish stress: A review. Phonology 20. 139-161.

Ito, Junko \& Armin Mester. 1999. Realignment. In René Kager, Harry van der Hulst \& Wim Zonneveld (eds.), The prosody-morphology interface, 188-217. Cambridge \& New York: Cambridge University Press.

Kabak, Barış \& Irene Vogel. 2001. The phonological word and stress assignment in Turkish. Phonology 18. 315-360.

Kager, René. 1994. Ternary rhythm in alignment theory. Manuscript, Utrecht University. $<$ http://dspace.library.uu.nl/handle/1874/9821>

Kiparsky, Paul. 2000. Opacity and cyclicity. The Linguistic Review 17. 351-367.

McCarthy, John. 2003. OT constraints are categorical. Phonology 20. 75-138.

Melvold, Janis. 1989. Structure and stress in the phonology of Russian. Cambridge, MA: MIT dissertation.

Oswalt, Robert L. 1961. A Kashaya grammar (Southwestern Pomo). Berkeley, CA: University of California dissertation.

Oswalt, Robert L. 1964. Kashaya texts (University of California Publications in Linguistics 36). Berkeley \& Los Angeles: University of California Press.

Oswalt, Robert L. 1988. The floating accent of Kashaya. In William Shipley (ed.), In honor of Mary Haas, 611-621. Berlin: Mouton de Gruyter.

Oswalt, Robert L. 2005. Kashaya dictionary. Manuscript, California Language Archive, Survey of California and Other Indian Languages. University of California, Berkeley.

Pater, Joe. 2007. The locus of exceptionality: Morpheme-specific phonology as constraint indexation. In Leah Bateman, Michael O'Keefe, Ehren Reilly \& Adam Werle (eds.), Papers in Optimality Theory III (University of Massachusetts Occasional Papers in Linguistics 32). 259-296. Amherst, MA: Graduate Linguistics Students Association.

Poser, William. 1984. The phonetics and phonology of tone and intonation in Japanese. Cambridge, MA: MIT dissertation.

Prince, Alan \& Paul Smolensky. 2004. Optimality theory: Constraint interaction in generative grammar. Malden, MA: Blackwell.

Round, Erich. 2017. Phonological exceptionality is localized to phonological elements: The argument from learnability and Yidiny word-final deletion. In Claire Bowern, Laurence Horn \& Raffaella Zanuttini (eds.), On looking into words (and beyond): Structures, relations, analyses (Empirically Oriented Theoretical Morphology and Syntax 3), 59-98. Berlin: Language Science Press. 